\title{
IMPLEMENTASI KONSEP TRIPLE BOTTOM LINE DALAM PROGRAM CORPORATE SOCIAL RESPONSIBILITY DI HOTEL ALILA SEMINYAK
}

\section{IMPLEMENTATION OF TRIPLE BOTTOM LINE CONCEPT IN CORPORATE SOCIAL RESPONSIBILITY PROGRAM IN ALILA SEMINYAK HOTEL}

\author{
Ni Nengah Ariastini dan I Made Trisna Semara \\ Sekolah Tinggi Pariwisata Bali Internasional \\ Surel: ariastini.elf@gmail.com
}

\begin{abstract}
The concept of the Triple Bottom Line (TBL) confirms that in running a business, companies do not only pay attention to profits, but also contribute to society (people), and play an active role in protecting the environment (planet). One implementation of the TBL concept is the Corporate Social Responsibility (CSR). Alila Seminyak is one of the hotels that have been implemented CSR. However, the community stated that there were deficiencies in the program. Even though the company stated there were no obstacles during the program implementation. The purpose of this study is to find out how was the implementation of TBL concept in the CSR program at Alila Seminyak and how the evaluation of the program. The data collection techniques used are documentation study, in-depth interviews, and observations. The data analysis technique used is qualitative descriptive analysis technique. The results of the study are Alila Seminyak has implemented the TBL concept in CSR programs but it has not been maximized in the concept of people. The people are not involved in the planning and evaluation of the program, and evaluation of the program has not been carried out optimally, because it does not involve the recipient community and there is no evaluation of the achievement of program objectives.
\end{abstract}

Keywords: Community Involvement, Coorporate Social Responsibility, Program Evaluation, Triple Bottom Line

\begin{abstract}
ABSTRAK
Konsep Triple Bottom Line (TBL) menegaskan bahwa dalam menjalankan bisnis, perusahaan tidak hanya memperhatikan keuntungan, tetapi juga berkontribusi pada masyarakat (manusia), dan memainkan peran aktif dalam melindungi lingkungan (planet). Salah satu implementasi dari konsep TBL adalah Corporate Social Responsibility (CSR). Alila Seminyak adalah salah satu hotel yang telah menerapkan CSR. Namun, masyarakat menyatakan bahwa ada kekurangan dalam program ini. Meskipun perusahaan menyatakan tidak ada kendala selama implementasi program. Tujuan dari penelitian ini adalah untuk mengetahui bagaimana penerapan konsep TBL dalam program CSR di Alila Seminyak dan bagaimana evaluasi program. Teknik pengumpulan data yang digunakan adalah studi dokumentasi, wawancara mendalam, dan observasi. Teknik analisis data yang digunakan adalah teknik analisis deskriptif kualitatif. Hasil dari penelitian ini adalah Alila Seminyak telah menerapkan konsep TBL dalam program CSR tetapi belum dimaksimalkan dalam
\end{abstract}


konsep orang. Masyarakat tidak terlibat dalam perencanaan dan evaluasi program, dan evaluasi program belum dilakukan secara optimal, karena tidak melibatkan masyarakat penerima dan tidak ada evaluasi pencapaian tujuan program.

Kata kunci: Keterlibatan Masyarakat, Tanggung Jawab Sosial Perusahaan, Evaluasi Program, Triple Bottom Line

\section{PENDAHULUAN}

Konsep TBL menegaskan bahwa dalam menjalankan operasional perusahaan, selain mengejar profit, perusahaan juga harus dapat berkontribusi untuk masyarakat (people) dan berperan aktif dalam menjaga lingkungan (planet) (Elkington, 1994 dalam Felisia dan Limijaya, 2014).

Salah satu implementasi konsep TBL diwujudkan dalam program Corporate Social Responsibility (CSR). Program CSR merupakan tanggungjawab sosial perusahaan yang diharapkan dapat memberikan manfaat positif untuk komunitas sekitar perusahaan maupun masyarakat secara luas (Avicenia, 2014). Selain itu, pelaksanaan CSR juga diatur dalam Undang-Undang Perseroan Terbatas Nomor 40 Tahun 2007 yang menyatakan bahwa Perseroan memiliki kewajiban untuk melaksanakan tanggung jawab sosial dan lingkungan yang dianggarkan dan diperhitungkan sebagai biaya pelaksanaannya yang dilakukan dengan memperhatikan kepatutan dan kewajaran.

Alila Seminyak merupakan salah satu hotel yang melaksanakan program CSR. Alila Seminyak mulai melakukan program CSR pada tahun 2016, dengan beberapa program diantaranya educational aid for elementary schools, Bali Coins, dan "Food For Thoughts" scholarship program (Alilahotels.com, 2018). Program yang pertama adalah mendukung dua sekolah dasar yang ada di Kerobokan. Kedua, mengajak tamu untuk memberikan sumbangan bagi masyarakat kurang mampu dan yayasan-yayasan anak-anak yang ada di Bali. Ketiga, memberikan beasiswa untuk anak-anak yang tertarik belajar di dunia Food and Beverage. Dalam melaksanakan programnya, Alila Seminyak sudah mendapatkan respon positif dari penerima program. Seperti yang diungkapkan Kepala Sekolah SD N 2 Kerobokan, sekolah dasar di bawah pimpinannya merasa sangat terbantu dari sisi fasilitas. Selain itu, Alila Seminyak juga memberikan dukungan dalam proses belajar anak-anak sekolah dasar.

Namun, terdapat kekurangan dalam pengimplementasiannya, dimana masyarakat tidak dilibatkan, baik dalam perencanaan maupun evaluasi. Seperti yang dinyatakan Ibu Luluk, Alila Seminyak hanya memberikan informasi program yang telah disusun dan hanya mengkoordinasikan waktu pelaksanaan. Padahal keterlibatan masyarakat sangat penting dalam setiap tahapan proses CSR. Seperti yang dinyatakan oleh Nurbaiti dan Bambang (2017), dalam pengembangan komunitas harus ada keterlibatan aktif semua masyarakat pada proses kegiatan masyarakat.

Dengan tidak dilibatkannya masyarakat dalam setiap proses, dapat menimbulkan ketidaksesuaian dan ketidaktepasasaran program. Sofyanty et al. (2017) dalam penelitiannya juga menyatakan, terdapat permasalahan karena ketidaktepatan pelaksanaan CSR, dimana hotel Ibis yang melaksanakan CSR hanya ditujukan untuk beberapa orang tertentu dan bukan masyarakat secara luas. 
Keterlibatan masyarakat juga menyangkut peran dan fungsi dari elemen people dalam konsep Triple Bottom Line (Rosyda dan Nasdian, 2011).

Selain keterlibatan masyarakat, Alila Seminyak juga belum memiliki departemen khusus yang menangani CSR. Dengan tidak adanya tim khusus yang menangani, terdapat hambatan-hambatan dalam program. Hambatan tersebut adalah kurangnya waktu dan sumber daya manuaia, sehingga perencanaan, pelaksanaan, maupun evaluasi dilakukan dengan fleksibel. Padahal, evaluasi sangat penting dilakukan untuk mengukur sejauh mana efektivitas penerapan CSR (Wibisono, 2007 dalam Rosyda dan Nasdian, 2011).

Penelitian ini bertujuan untuk mengetahui bagaimana implementasi konsep TBL dalam program CSR di Alila Seminyak, serta mengetahui bagaimana evaluasi dari program CSR tersebut. Dengan dilakukannya penelitian ini diharapkan dapat memberikan manfaat bagi hotel, mahasiswa, maupun kampus untuk menyusun strategi-strategi terkait pengembangan konsep triple bottom line pada program Corporate Social Responsibility di masa depan dan dapat menjadi acuan bagi penelitian selanjutnya.

\section{TINJAUAN PUSTAKA}

\section{A. Triple Bottom Line}

Konsep Triple Bottom Line (TBL) merupakan konsep yang dikembangkan oleh John Elkington pada tahun 1997 melalui bukunya yang berjudul "Cannibals with Fork, the Triple Bottom Line of Twentieth Century Business” (Yanti dan Rasmini, 2015). Elkington menyatakan bahwa selain mengejar profit, perusahaan harus memperhatikan dan terlibat pada pemenuhan kesejahteraan masyarakat (people) dan berkontribusi aktif dalam menjaga kelestarian lingkungan (planet). Hingga saat ini, konsep TBL juga dikemukakan oleh beberapae ahli. Andrew Savitz (2006) dalam Slaper dan Hall (2011) menyatakan bahwa, TBL merupakan intisari dari keberlanjutan dengan mengukur dampak dari kegiatan organisasi di dunia, termasuk profitabilitas dan pemegang saham, sosial, masyarakat, dan lingkungan. Sedangkan Smith dan Sharicz (2011) menyatakan bahwa TBL merupakan,

"The result of the activities of an organization voluntary or governed by law, that demonstrate the ability of the organization to maintain viable its business operations (including financial viability as appropriate) whilst not negatively impacting any social or ecological systems."

TBL merupakan unsur penting yang harus diperhatikan oleh perusahaan. TBL dapat menjadi tolak ukur perusahaan, dengan tidak hanya memperhatikan sisi ekonomi, namun juga dampak yang ditimbulkan baik positif maupun negatif terhadap sosial dan lingkungan.

Ketiga aspek TBL memiliki hubungan dan keterkaitan yang kuat. Aulia dan Kertawijaya (2013) menggambarkan dari aspek ekonomi, perusahaan harus fokus terhadap keuntungannya demi keberlangsungan hidup perusahaan, dari aspek sosial, perusahaan harus memiliki komitmen kepada masyarakat untuk memberikan manfaat sebesar-besarnya, dan dari aspek lingkungan, semua kegiatan perusahaan terkait erat dengan lingkungan. Wibisono (2007) dalam Sofyanty, et al (2017) juga menjelaskan keterkaitan mengenai ketiga aspek TBL, profit merupakan pendapatan tambahan yang digunakan untuk menjamin kelangsungan hidup perusahaan, people merupakan masyarakat yang menjadi salah satu unsur pendukung yang menentukan 
keberlanjutan perusahaan, dan planet merupakan lingkungan yang memiliki hubungan sebab-akibat dengan perusahaan.

Konsep TBL juga memiliki keterkaitan dengan konsep Tri Hita Karana. Perbedaannya terletak pada konsep TBL yang digunakan dalam dunia usaha, yang menjaga keseimbangan antara laba, masyarakat, dan lingkungan sedangkan Tri Hita Karana menjaga harmonisasi ke-Tuhan-an, masyarakat, dan lingkungan (Hutasoit dan Wau, 2017). Sehingga, pada akhirnya adalah menjaga keseimbangan unsur-unsur tersebut untuk mencapai keberlanjutan.

Dari pemaparan tersebut, dapat dinyatakan perusahaan harus dapat menyeimbangkan ekonomi agar dapat memberikan manfaat kepada masyarakat dan menjaga keseimbangan lingkungan dari setiap aktivitasnya. Perusahaan dalam menjalankan ketiga aspek TBL tersebut, dapat melaksanakannya dalam program CSR. Hal tersebut dikarenakan pada dasarnya konsep TBL merupakan intisari dari prinsip CSR (Elkington, 1997 dalam Lelisari dan Nasution, 2017).

\section{B. Corporate Social Responsibility}

CSR secara umum diartikan sebagai kumpulan kebijakan dan praktek yang berhubungan dengan stakeholder, nilai-nilai, pemenuhan ketentuan hukum, penghargaan masyarakat dan lingkungan, serta komitmen perusahaan untuk berkontribusi dalam pembangunan berkelanjutan. CSR telah diatur dalam ISO 26000 (Prastowo dan Huda 2011), dimana bunyinya adalah sebagai berikut:

"Responsibility of organization for the impacts of its decisions and activities on society and the environment, through transparent and ethical behavior that contributes to sustainable development, including health and the welfare of society; takes into account the expectations of stakeholders; is in compliance with applicable law and consistent with international norms of behavior; and is integrated throughout the organization and practiced in its relationship."

Retnaningsih (2015) juga memaparkan CSR merupakan program perusahaan untuk menjaga kelangsungan usahanya dengan memperhatikan hubungan internal dan eksternal perusahaan. Dari pemaparan-pemaparan tersebut, dapat dilihat bahwa tanggung jawab sosial perusahaan memiliki peran yang penting dalam masyarakat maupun lingkungan. Hal ini dikarenakan, akibat dari aktivitas perusahaan dapat memberikan dampak ke masyarakat maupun lingkungan. Sehingga perusahaan harus bertanggungjawab agar tetap bersinergi dengan baik antara ekonomi dengan sosial masyarakat dan lingkungan.

Roza (2014) dalam penelitiannya menyatakan, dalam melakukan perencanaan CSR harus dapat merumuskan tujuan dengan jelas, melibatkan pihak lain seperti pemerintah, LSM, masyarakat lokal, dan lain sebagianya, dan pelaksanaan program harus selalu dipantau dan dievaluasi sejauh mana tujuan program telah tercapai. Maygarindra dan Maghviroh (2012), juga menyatakan dalam perencanaan terdapat tahapan-tahapan yang harus diperhatikan, yaitu penetapan filosofi dan misi, penetapan tujuan dan strategi, penyusunan program, dan penyusunan anggaran. Begitupun Pranoto dan Yusuf (2014) yang menyatakan agar mampu menerapkan CSR yang baik, penerapannya memperhatikan perencanaan dan pelaksanaan program. Dengan dilaksanakannya perencanaa, pelaksanaan, serta evaluasi dari program dapat melihat kekurangan maupun kelebihan program, sehingga dapat dilakukan perbaikan untuk program yang akan dilakukan. 
Begitupun dalam pengimplementasian program, terdapat kondisi-kondisi yang harus dipenuhi. Program CSR memperoleh persetujuan dan dukungan dari pihak yang terlibat, ditetapkannya pola hubungan diantara pihak-pihak yang terlibat secara jelas, dan pengelolaan program yang baik (Roza, 2014). Adianto (2011) dalam Pranoto dan Yusuf (2014) juga menyatakan adanya partisipasi masyarakat sebagai pemicu kemandirian dan proses pemberdayaan adalah komponen yang sangat penting. Masyarakat memiliki peran yang sangat penting di dalamnya, khusunya pada program yang berbasis pengembangan ekonomi mandiri dan pemberdayaan masyarakat (Pranoto dan Yusuf, 2014).

Menurut Cohen dan Uphoff (1980) dalam Afifah (2011), partisipasi masyarakat dilihat dari keterlibatan masyarakat dimulai dari tahap pembuatan keputusan, penerapan keputusan, penikmatan hasil, dan evaluasi program. Afifah (2011) dalam penelitiannya juga menyatakan perwujudan program CSR terhadap masyarakat dilakukan dengan berbagai program pengembangan masyarakat, dimana masyarakat dilibatkan bukan sebagai objek melainkan sebagai subjek pembangunan. Dari pemaparan-pemaparan tersebut, dapat dinyatakan keterlibatan masyarakat memegang peran besar dalam implementasi program CSR. Sehingga, keterlibatan masyarakat dalam setiap proses sangat diperlukan. Dengan adanya sinergi antara perusahaan dan masyarakat dapat menjadi faktor optimalisasi pelaksanaan program.

Selain sisi sosial, program CSR dari sisi lingkungan juga harus diperhatikan. Sunaryo (2013) dalam penelitiannya menyatakan bahwa, dalam menciptakan kelestarian lingkungan program-program CSR yang dilaksanakan berorientasi pada pembangunan berkelanjutan. Program CSR dari sisi lingkungan dapat dilihat dari program pembiayaan berdasarkan sumberdaya alam setempat, program rehabilitasi dan pengadaan fasilitas sekolah, program kesehatan lingkungan, dan program konservasi alam dan lingkungan (Sari et al., 2015). Dari pemaparan-pemaparan tersebut, dapat dilihat bahwa dalam menjaga keseimbangan lingkungan dari dampak yang ditimbulkan, dapat dilakukan dengan pembangunan berkelanjutan. Dimana setiap kegiatan yang dilaksanakannya berorientasi untuk menjaga lingkungan sekitar.

Setelah implementasi, diperlukan proses evaluasi untuk mengukur efektivitas dari program CSR yang dilaksanakan. Evaluasi harus dilakukan untuk mengetahui tingkat keberhasilan program dan hasil dari evaluasi merupakan masukan bagi perencana dan realisasi program selanjutnya (Rahman, 2009 dalam Julianda, 2013).

\section{METODE PENELITIAN}

Penelitian ini merupakan penelitian kualitatif. Penelitian dilaksanakan di Alila Seminyak selama 5 bulan, dimulai bulan Mei - September 2019. Teknik pengumpulan data yang digunakan adalah studi dokumentasi terhadap dokumen laporan kegiatan CSR, anggaran CSR, laporan penggunaan dana CSR, dan data karyawan, wawancara mendalam dengan key informan selaku perencana dan pelaksana CSR dan penerima program CSR, dan observasi non partisipan terhadap pengimplementasian CSR di Alila Seminyak. Teknik analisis data yang digunakan adalah analisis deskriptif kualitatif. Data-data yang diperoleh dari hasil wawancara, observasi, dan dokumentasi akan direduksi lalu dideskripsikan kembali secara kualitatif (Pantiyasa, 2013) 


\section{HASIL DAN PEMBAHASAN}

\section{A. Implementasi Konsep TBL dalam Program CSR di Alila Seminyak}

Alila Seminyak sudah mulai membuat perencanaan untuk melakukan program CSR pada tahun 2015. Terlepas dari Undang-Undang No.40 tahun 2007 tentang Perseroan Terbatas yang mengharuskan setiap perusahaan melakukan tanggung jawab sosial, Alila Seminyak melaksankan program CSR tersebut dikarenakan memiliki misi untuk berkomitmen dalam bertanggung jawab terhadap keberlanjutan. Keberlanjutan yang dimaksud adalah dalam bertanggung jawab terhadap lingkungan, sosial, maupun masyarakat sekitar Alila Seminyak. Dimana kegiatan-kegiatannya diwujudkan dengan menjaga harmonisasi antara ketiga unsur tersebut.

Tim perencana dan pelaksana program CSR di Alila Seminyak, menyatakan bahwa program CSR dilakukan berlandaskan konsep Tri Hita Karana. Program CSR yang dilakukan selalu berusaha menjaga hubungan baik dengan masyarakat dan lingkungan. Konsep Tri Hita Karana sendiri sejalan dengan konsep Triple Bottom Line yang harus diperhatikan oleh setiap perusahaan (Hutasoit dan Wau, 2017). Namun, perbedaannya konsep Triple Bottom Line juga memandang dari sisi ekonomi perusahaan.

Dalam melaksanakan program CSR, terdapat tahapan-tahapan yang harus dilaksanakan. Tahapan pertama adalah tahap perencanaan program (Maygarindra dan Maghviroh, 2012; Pranoto dan Yusuf, 2014). Bapak Heindra Pradana menyatakan tim perencana dan pelaksana program CSR di Alila Seminyak adalah Departemen Human Resources dan Departemen Sales \& Marketing, yang berada di bawah tanggung jawab Director of Human Resources.

Perencanaan dilakukan dengan berdiskusi dengan tim perencana mengenai program dan waktu pelaksanaan. Setelah program dirancang, anggaran CSR akan diajukan ke bagian Finance. Anggaran untuk CSR telah dirancang untuk program CSR satu tahun dengan sebutan Donation, sehingga anggaran untuk setiap program dibuat menyesuaikan dengan anggaran setiap bulannya. Setelah program ditetapkan, akan diinformasikan ke pihak penerima program.

Tabel 1. Program CSR di Alila Seminyak

\begin{tabular}{|l|l|l|}
\hline No & $\begin{array}{l}\text { Konsep } \\
\text { TBL }\end{array}$ & Program CSR \\
\hline 1 & People & - Bantuan untuk SD N 1 Kerobokan Kelod dan SD N 2 \\
& & Kerobokan Kelod \\
& & - Bali cCoins \\
& & - Dharma Wacana \\
& & - Sponsorship \\
\hline 2 & Planet & - Zero Waste to Landfill \\
& & - Bakti Sosial \\
\hline
\end{tabular}

Dapat dilihat pada Tabel 1., program-program yang dilaksanakan Alila Seminyak yang mengimplementasikan konsep people dan planet ke dalam program CSR. Namun, implementasi yang dilakukan belum maksimal dari sisi people. Dari sisi planet, Alila Seminyak telah berkontribusi aktif dalam menjaga kelestarian lingkungan. Sesuai dengan konsep planet yang dinyatakan oleh Elkington dalam 
Yanti dan Rasmini (2015). Khusunya pada program Zero Waste to Landfill, limbah yang dihasilkan dipertanggungjawabkan dengan tidak membuang langsung ke TPA, melainkan diolah kembali. Selain itu, Alila Seminyak juga menyediakan fasilitas tempat sampah yang berbeda sesuai jenis sampah di SD N 1 Kerobokan Kelod dan SD N 2 Kerobokan Kelod. Sehingga dapat menciptakan keberlanjutan dari lingkungan (Sunaryo, 2013; Sari et al., 2015).

Dari sisi people, sudah ada hubungan yang baik antara perusahaan dengan masyarakat. Hal tersebut dapat dilihat dari respon positif Kelian Adat Br. Batubelig yang menyatakan program-program yang dilaksanakan Alila Seminyak sudah baik. Namun, disisi lain belum ada partisipasi masyarakat dalam perencanaan. Dimana masyarakat seharusnya mengkoordinasikan apa yang benar-benar diperlukan untuk kesejahteraannya, sehingga tanggapan serta partisipasi masyarakat menjadi tolak ukur dari pencapaian tujuan program (Pranoto dan Yusuf, 2014). Dampaknya adalah program yang dilakukan dinyatakan mendapatkan respon positif, namun belum diketahui apakah benar-benar bermanfaat dan dibutuhkan oleh masyarakat. Sedangkan konsep people adalah memberikan manfaat yang sebesar-besarnya kepada masyarakat (Aulia dan Kertawijaya, 2013). Sehingga, dapat dinyatakan Alila Seminyak belum mengimplementasikan konsep people secara maksimal.

\section{B. Evaluasi Program CSR di Alila Seminyak}

Dalam pengimplementasian, terdapat kondisi-kondisi yang harus dipenuhi. Kondisikondisi tersebut adalah adanya persetujuan dari pihak yang terlibat, ditetapkannya pola hubungan antara pihak-pihak yang terkait, serta dikelolanya program dengan baik (Roza, 2014). Dari kondisi-kondisi tersebut, Alila Seminyak telah mendapatkan persetujuan dari pihak penerima program, telah menjalin hubungan dengan pihak penerima program, namun belum mengelolanya dengan maksimal. Belum maksimalnya pengelolaan dapat dilihat dari penggunaan anggaran CSR. Terdapat ketimpangan dari anggaran CSR dengan penggunaannya. Ketimpangan tersebut dapat dilihat dari Diagram 1.

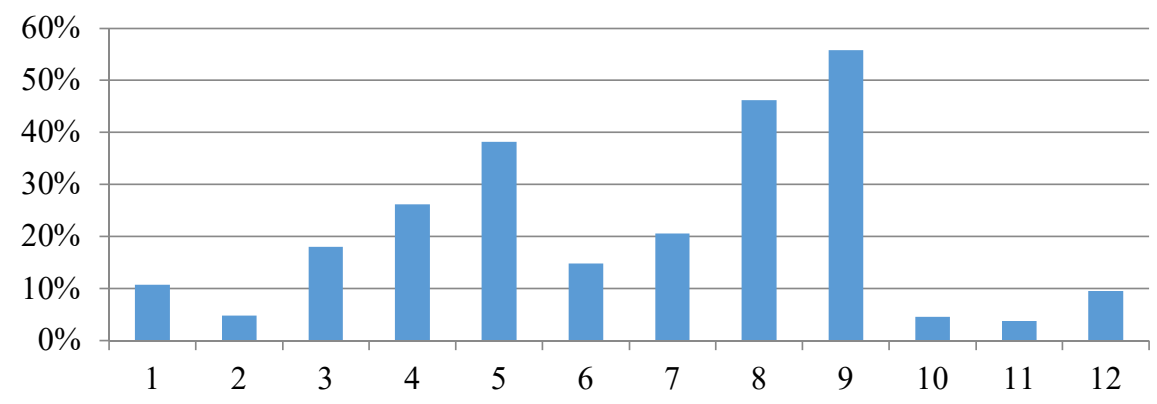

Gambar 1. Penggunaan Dana CSK ZU I8 Sumber: Report Donation 2018 Alila Seminyak

Pada DIAGRAM 1, dapat dilihat penggunaan dana setiap bulan belum mendekati 100\%. Dimana dari seluruh anggaran CSR tahun 2018, yang digunakan hanya sebesar $14 \%$. Dengan ketidak sesuaian tersebut, dapat dinyatakan penggunaan anggaran CSR belum maksimal. 
Selain dari sisi anggaran, Alila Seminyak juga tidak merumuskan tujuan program secara tertulis dan tidak membuat laporan kegiatan. Sehingga, ketercapaian program belum dapat diukur. Dengan tidak adanya laporan kegiatan, tidak diketahui bagaimana kekurangan maupun kelebihan dari program.

Evaluasi yang dilakukan bersama tim perencana dan pelaksana dilaksanakan secara lisan. Hasil dari evaluasi yang dilakukan, program yang dilaksanakan sudah berjalan lancar. Sedangkan kendala-kendala yang ditemui, hanya dari sisi teknis saja saat melangsungkan program.

Padahal, dalam setiap proses CSR dimulai dari perencanaan, pelaksanaa, maupun evaluasi harus ada partisipasi pihak penerima program (Roza, 2014). Sehingga masyarakat dapat menilai secara langsung bagaimana program yang dilaksanakan dan kekurangan-kekurangan program. Berdasarkan pemaparan tersebut, dapat dinyatakan evaluasi dari implementasi program CSR di Alila Seminyak sudah dilaksanakan, namun belum maksimal.

\section{KESIMPULAN}

Berdasarkan hasil penelitian, dapat disimpulkan konsep TBL dari sisi people dan planet telah diimplementasikan dalam program CSR. Namun, implementasi yang dilakukan belum maksimal sesuai dengan kaidah TBL maupun CSR. Ketidaksesuaian tersebut dilihat dari sisi people, belum adanya keterlibatan masyarakat penerima program dalam perencanaan dan evaluasi. Selain itu, perencanaan tidak dilakukan secara terstruktur baik dalam perumusan tujuan, strategi, maupun kebijakan. Evaluasi program CSR juga belum melibatkan masyarakat dan tidak dibuatkan dalam bentuk laporan kegiatan. Sehingga, tujuan program tidak dapat diukur ketercapaiannya maupun kekurangan dan kelebihan program.

\section{DAFTAR PUSTAKA}

Afifah, Dzul. 2011. Persepsi dan Partisipasi Masyarakat Terhadap Kegiatan Corporate Social Responsibility (CSR) oleh PT. Wirakarya Sakti Dalam Penguatan Ekonomi Lokal. Skripsi. Institut Pertanian Bogor.

Alilahotels.com. 2018. Sustainable Tourism. https://www.alilahotels.com/aboutalila/sustainable-tourism. Diakses 8 November 2018.

Aulia Z, Sandra dan Kartawijaya, Tb. Mh. Idris. 2013. Analisis Pengungkapan Triple Bottom Line dan Faktor yang Mempengaruhi; Lintas Negara Indonesia dan Jepang. Jurnal Vokasi Indonesia. Vol. 1. No. 1. Hal. 16-34.

Avicenia, Ressi Putri. 2014. Analisa Implementasi Konsep Triple Bottom Line Pada Program Corporate Social Responsibility Sebagai Bagian Dari Strategi Hubungan Masyarakat Perusahaan (Studi Kasus: Program C.A.F.E Practice Starbucks). Makalah Non-Seminar. Universitas Indonesia .

Felisia dan Limijaya, Amelia. 2014. Triple Bottom Line dan Sustainability. Bina Ekonomi Majalah Ilmiah Fakultas Ekonomi Unpar. Vol. 18. No. 1. Hal. 1427.

Hutasoit, Hasudunungan dan Wau, Redaktur. 2017. Menuju Sustainability Dengan Tri Hita Karana (Sebuah Studi Interpretif Pada Masyarakat Bali). Jurnal Manajemen. Vol. 13. No. 2. Hal. 85-191. 
Julianda, Hijriah. 2013. Implementasi Corporate Social Responsibility Pada PT. Maruki Internasional Indonesia. Skripsi. Universitas Hasanuddin.

Lelisari dan Nasution, Bismar. 2017. Corporate Social Responsibility Perusahaan Pertambangan Terhadap Masyarakat dan Lingkungan Untuk Pembangunan Berkelanjutan. GaneC Swara. Vol. 11. No. 1. Hal. 8-18.

Maygarindra, Putranti Budi dan Maghviroh, Rovila El. 2012. Analisis Alokasi Dana Corporate Social Responsibility Serta Pelaporan Sustainability Report Berdasarkan Global Reporting Initiative (Gri G3) di PT. Pembangkitan Jawa Bali. The Indonesian Accounting Review. Vol. 2. No. 2. Hal 173-184.

Pantiyasa. 2013. Metode Penelitian. CV Andi Yogyakarta.

Pranoto, Asa Ria., dan Yusuf, Dede. 2014. Program CSR Berbasis Pemberdayaan Masyarakat Menuju Kemandirian Ekonomi Pasca Tambang di Desa Sarijaya. Jurnal Ilmu Sosial dan Ilmu Politik. Vol. 18. No. 1. Hal 39-50

Prastowo, Joko dan Huda, Miftahul. 2011. Corporate Social Responsibility, Kunci Meraih Kemuliaan Bisnis. Yogyakarta: Samudera Biru.

Retnaningsih, Hartini. 2015. Permasalahan Corporate Social Responsibility Dalam Rangka Pemberdayaan Masyarakat. Aspirasi. Vol. 6. No. 2. Hal. 177-188.

Rosyda, Isma dan Nasdian, Fredian Tonny. 2011. Partisipasi Masyarakat Dan Stakeholder Dalam Penyelenggaraan Program Corporate Social Responsibility (CSR) dan Dampaknya Terhadap Komunitas Perdesaan. Jurnal Transdisiplin Sosiologi, Komunikasi, dan Ekologi Manusia. Vol. 5. No. 1. Hal. 51-70.

Roza, Suswita. 2014. Perencanaan, Implementasi, dan Evaluasi Program CSR (Corporate Social Responsibility). Mankeu. Vol. 3. No.1. Hal 374-463.

Sari, Enda Kartika et al. 2015. Implementasi Program CSR Lingkungan PT. Semen Baturaja (Persero) Tbk Terhadap Kondisi Sosial Ekonomi Masyarakat di Kabupaten Ogan Komering Ulu Sumatera Selatan. Jurnal Ilmu Lingkungan. Vol. 13. No. 1. Hal. 42-54.

Slaper, T.F dan Hall, T.J. 2011. The Triple Bottom Line: What Is It And How Does It Work?. Indiana Business Review. Spring 2011.

Smith, P.A.C dan Sharicz, C. 2011. The Shift Needed For Sustainability. The Learning Organization. Vol. 18. No. 1. Hal. 73-86.

Sofyanty, Yossie Ria, dkk. 2017. Analisis Penerapan CSR dan Dampaknya Terhadap Kehidupan Sosial Ekonomi Masyarakat (Studi Kasus Pada Hotel Ibis Surabaya City Center). Jurnal Administrasi Bisnis. Vol. 42. No. 2. Hal. 26-31.

Sunaryo. 2013. Corporate Social Responsibility (CSR) Dalam Perspektif Pembangunan Berkelanjutan. Jurnal Ilmu Hukum. Vol. 7. No. 1. Hal. 264267.

Undang-Undang Republik Indonesia. 2007. Undang-Undang RI. No. 40 Tahun 2007 Tentang Perseroan Terbatas.

Yanti, Fitri dan Rasmini, Ni Ketut. 2015. Analisis Pengungkapan Triple Bottom Line dan Faktor yang Mempengaruhi: Studi di Perusahaan Indonesia dan Singapura. E-Jurnal Akuntansi Universitas Udayana. Vol. 13. No. 2. Hal. 499-512. 